\title{
Digitalisation of Energy Systems within the Context of Existing Policy Frameworks: An Assessment of Sustainable Energy Transitions in Africa
}

Fortune Nwaiwu ( $\sim$ nwaiwu@utb.cz)

Tomas Bata University

Original article

Keywords: Blockchain, Smart Grids, Digital Technologies, Social and Solidarity Economy, sub-Saharan Africa

Posted Date: January 20th, 2021

DOI: https://doi.org/10.21203/rs.3.rs-148680/v1

License: (c) (1) This work is licensed under a Creative Commons Attribution 4.0 International License.

Read Full License 


\section{Abstract}

\section{Background}

Digital technologies have unique characteristics for achieving radically disruptive transitions within the energy sector. They provide opportunities for new production and consumption models between micro producers and consumers of electricity within communities in a way that transforms the traditional energy generation and consumption model. The study critically assessed the digitalisation of energy systems in Africa within the context of existing policy frameworks in the quest to achieve sustainable energy transitions in Africa. It investigated how digital technologies such as blockchain, digital platforms and smart grids were adopted and implemented within the energy sector in achieving new energy production and consumption models that are both environmentally sustainable and socially inclusive, this assessment was done within the context of existing policy and regulatory frameworks of the society where the use cases were domiciled.

\section{Methods}

The research adopted a qualitative methodological approach which was done in three stages - a document analysis that reviewed relevant literature on the energy sector and policies within the sector for Nigeria and South Africa; the next step involved a comparative case study is conducted to assess the characteristics of how digital technologies was deployed in mediating sustainable energy transitions; finally, the outcomes of the comparative case studies was then situated within the context of existing policies within the countries covered by the study

\section{Results}

Results from the research indicate that Africa is still in the early stages of adoption and application of digital technologies such as blockchain and smart grids within the energy sector, the results also showed the disconnect between policy environment and industry efforts in achieving digital technologies mediated sustainable energy transitions in Africa. The current applications as exemplified in the use cases by the three companies covered in this study indicates that Africa's sustainable energy transitions is in a rudimentary or early adoption stage, and they are not currently aided by the policy environments in which such projects are domiciled.

\section{Conclusions}

The research provides deep insights into the current state and developments within the energy sector especially in relations to how digital technologies are being adopted and implemented in solving the energy poverty prevalent across sub-Saharan Africa.

\section{Background}


Recent estimates indicate $97 \%$ of the world's population growth through 2030 ( 1.3 billion more people) will occur in the developing world. Countries in sub-Saharan Africa alone are projected to add over a billion people to the global population by $2050[1,2]$. This will result in growing energy demands. In anticipation of the challenges that would result from this population growth, the United Nations has prioritised the need for responsible and equitable energy pathways through their Sustainable Development Goals (SDGs). With a set of goals emphasizing access to affordable and reliable energy services [3]. Despite the crucial role of electricity in the proper functioning of society, about 1.2 billion people, located mainly in sub-Saharan Africa, still lack access to electricity. Access to energy has gained prominence as a topical subject in both academic and non-academic discourse, given the varied services provided through electricity. Hence, the need to expand access to electricity has resulted in a growing body of research on energy transitions with particular focus on underserved regions of the world especially in sub-Saharan Africa [4].

It is in the light of the critical role of energy to socioeconomic development and human wellbeing in every society, and the growing concerns about climate change, focus on poverty eradication and energy security, that sustainable energy transitions now occupy a place of prominence among stakeholders in policy circles, industry and the academia around the world [5]. Hence, the need to explore digital technology mediated sustainable energy transitions solutions for underserved communities, offers opportunities for a pathway to achieving socioeconomic development that is inclusive, sustainable and has the potentials of alleviating poverty and improving overall wellbeing of people at the bottom of the socioeconomic pyramid especially in societies across Sub-Saharan Africa (SSA). Firstly, it is imperative to understand what technological artefacts fall under the classification of "digital technologies".

According to Bharadwaj et.al. [6], digital technologies are electronic tools, systems, devices and resources that generate store or process data, they can be viewed as combinations of information, computing, communication, and connectivity technologies. Yoo et.al [7] argue that digital technologies differ from earlier technologies in three unique characteristics: (1) the re-programmability that separates the functional logic of a device from its physical embodiment, (2) the homogenisation of data that allows for storing, transmitting, and processing digital contents using the same devices and networks, as well as (3) the self-referential nature yielding positive network externalities that further accelerate the creation and availability of digital devices, networks, services, and contents [Yoo et al., 2010 as cited in 8]. Finally, examples of digital technologies include digital platforms (social media web platforms - Facebook, Twitter, LinkedIn, etc., ecommerce portals - Amazon, Alibaba, Ebay, etc., Uber, AirBnb etc.), online games and applications, blockchain technology, productivity applications, cloud computing, interoperable systems, cyber-physical systems employed in manufacturing automation processes, and mobile devices, etc. [9-11].

Digital technologies can be deployed to facilitate new economic models that address production and consumption especially in relations to sustainable energy transitions which mitigates resource impacts through digitally enabled optimisation of processes. Evidence from research has shown that optimisation of industrial processes either increases energy use or accelerates production or consumption. [12-16]. In 
view of the disruptive nature of digital technologies, and the inherent promise of achieving new and efficient models that displace existing production and consumption models in society in general and within business environments in particular, stakeholders now see the need to apply particular digital technologies such as blockchain and smart grids in the pursuit of sustainable energy transitions, with the particular objective of increasing access to energy to underserved communities such as found in subSaharan Africa [17-19].

In view of the current state of developments within the energy sector across sub-Saharan Africa, there is a lack of critical assessment of the digital technologies mediated sustainable energy transitions. This creates gaps of synergy between industry stakeholders and public sector policy drivers, thereby leading to chaotic, fragmented and often conflicting nature of evolution within the energy sector which may be counterproductive in the long run. Edomah [20] argues that policy makers play a vital role in governing transitions in any given society through established institutional frameworks, and that energy infrastructure choices are influenced and ultimately determined by institutional dynamics and structures.

This informs the need for scientific inquiry that would investigate the digitalisation of energy systems in sub-Saharan Africa, in the quest to achieve sustainable energy transitions. This will be done in tandem with existing policy and regulatory environments to identify possible areas of conflict that may become barriers to digital technologies mediated sustainable energy transitions. The research also looks at how digital technologies such as blockchain and smart grids are being adopted and implemented with the energy sector in achieving new energy production and consumption models that are both environmentally sustainable and socially inclusive. Finally, it addresses how digitalisation is transforming the energy sector across the world, with focus on developments in sub-Saharan Africa.

A qualitative methodological approach involving comparative case studies of the implementation of blockchain and smart grids within the energy sector. It also involves extensive review of relevant business and academic literatures focused on the subject area for the research. The use of a case study research design is particularly useful because of its potential to investigate a contemporary phenomenon within its real-life context especially when the boundaries between phenomenon and context are not clearly evident, and in which multiple sources of evidence are required [21-23]. The research contributes to the existing body of knowledge on digital technologies, blockchain technology and social and solidarity economy from an African perspective. The output will help policy makers better understand the landscape and dynamics of emergence, adoption and use of blockchain technology and how it can help achieve inclusive and sustainable development that would in turn promote gender equality, decent work, and food and livelihoods security.

\section{Current State Of The Energy Sector In Africa}

In spite of its immense energy resources endowments, most people in Sub-Saharan Africa face severe energy shortages with its attendant socioeconomic consequences which often manifests in high rates of poverty and underdevelopment [24]. To put into perspective the abysmal state of energy poverty in Africa, 
it is instructive to note that the current total generation capacity of 48 countries in sub-Saharan Africa stands at 68 Gigawatts of electricity, this is just about what a country like Spain currently generates, and if South Africa is excluded, the generation capacity of the remaining 47 countries drops to about 28 Gigawatt (GW) which is equivalent to what Argentina generates, and about $25 \%$ of this 28 Gigawatt is not achieved as a result of several factors which includes aging plants, unreliable supply of necessary fuels for electricity generation, and poor maintenance of generating plants $[25,26]$. Coupled with the severe shortage faced by many countries across the region is an unequal distribution problem which leaves many households in the rural areas disconnected from distributed networks when compared to those in the urban areas. Hence, Africans are faced with a twin energy challenge of energy poverty and high rate of energy inequality [27].

Also, in terms of sustainable energy transitions, African countries dominate the list of the worst performers across the world. According to the World Economic Forum's Energy Transition Index (ETI) ranking for 2019, majority of the countries occupying the bottom table of the ranking of 115 countries where from sub-Saharan Africa. Africa's two largest economies (Nigeria and South Africa) were ranked 109 and 114 respectively; the ETI provides a framework to benchmark and support countries in their energy transition efforts considering their current energy system performance, and the readiness of their macro-economic, social and regulatory environment for energy transition [28]. Kaseke and Hosking [29] argue that energy is a prerequisite for economic growth and development, they further stated that the relationship between economic growth and electrical power demand is positively correlated. This view is supported by several researchers who have investigated the relationship between economic growth and energy/electricity demand within societies [30-32]. Nevertheless, new challenges such as climate change and environmental sustainability makes it imperative for African countries to re-evaluate their energy systems and rejig them to become more efficient and environmentally friendly.

As energy demand in countries across sub-Saharan Africa continues to grow, so also is the pressure on available supply options. This has resulted in tensions supply and demand that threatens energy security, which in turn hampers socioeconomic development. Hence the need to explore avenues for achieving sustainable energy transitions in Africa [19]. Sub-Saharan Africa's energy supply is dominated by two main sources, they are: cheap energy sources such as fuel wood-biomass and charcoal; and modern industrial energy sources such as hydro power and fossil fuel based sources (gas and petroleum). These industrial energy sources are not readily available sources for electrification of rural areas because of the lack of infrastructure and capital required to make them available for use [27]. Between 2000 and 2015, the demand for electrification in sub-Saharan Africa grew by $45 \%$, and this demand is projected to triple by 2030. This projected rise in demand for electrification offers huge potential for investments in the sector, especially those that focus on the use of renewable energy sources such as wind, solar and hydro power $[24,27]$.

According to Bos, Chaplin, and Mamun [33], some of the challenges faced by governments in many African countries in their quest to expand to grid electricity are: the huge investments required, lack of requisite manpower needed in rolling out electrification projects, low take-up rates by potential 
consumers, as well as other institutional and supply-side hurdles. They commented that the most commonly cited challenge is the enormous expense of extending lines to remote and often sparsely populated rural areas, examples include in Western Kenya where the median infrastructure investment per connection was $\$ 2427$ because of low connection rates and in Uganda where estimates place the cost of extending electricity lines at $\$ 8000$ or more per connection in rural areas. In relations to take-up rates, they also refer to evidence from Botswana which showed that only $12 \%$ of households in electrified villages connected to the grid, the case in Ethiopia was such that only $39 \%$ of households in electrified communities connected to the grid, and in rural and peri-urban parts of Tanzania connection rates were around $21 \% 2$ to 3 years after the lines were built.

The attendant consequence of the energy poverty within sub-Saharan Africa has led to a situation whereby people are forced to generate their own electricity often within the confines of their homes using in most cases fossil fuel- based electricity generating sets and other solutions, which has led to massive fragmentation within the energy space across sub-Saharan Africa. Examples of such fragmentation include "under-the-grid" electrification solutions which offer simplicity, speed and agility, coupled with short installation time, they serve as reliable electricity alternatives for informal settlements and households. The Pay-as-you-go solar systems and appliances currently in use across Kenya provided by M-Kopa, which is a Kenyan firm that is expanding across East Africa and selling its solar-powered battery systems is an example, the package includes a torch and a mobile-phone charger. Their solution provides a much lower barrier to entry when compared to the high upfront connection costs of on-grid solutions, a 15-watt solar home system costs on average USD \$9 per month for 36 months after which point the household owns its system, and ; evidence shows that the willingness to pay for decentralised renewables is much higher than a grid connection because they are seen as more reliable [34, 35].

\section{Research Design}

The research adopts a qualitative methodological approach, and it proceeds in three stages - firstly, a document analysis is conducted to review and analyse energy sector related policy documents for Nigeria and South Africa, this is necessary to assess their focus on sustainable energy transitions and also if they incorporate policy provisions that cater to digital technology mediation of sustainable energy transitions; secondly, a comparative case study analysis is conducted to assess the characteristics of the use cases covered by the case studies in terms of how digital technologies is used to mediate sustainable energy transitions; finally, the outcomes of the comparative case studies is now situated within the context of existing policy frameworks within the jurisdiction where such use case is domiciled, this is imperative to establish fitness and synergy between practice as it relates to industry and the policy environment, this is necessary considering the opinion of Edomah [20], who argues that the relationship between resources, institutions, and political structures in the governance of energy infrastructure is quite complex; and that energy transitions were subject to influence by government policies implemented within and through institutions, hence the need for increased partnership and interaction between public and private institutions in the governance and provision of energy infrastructure. 
Of interest in the selection criteria were projects with use case that involved the adoption and implementation of digital technologies such as blockchain, smart grid technologies, and platformisation within the energy sector. According to Woodside \& Wilson [36], case study research presents an in-depth examination which is often undertaken over a time period, and of a single case that focuses on issues such as a policy statement, programme, intervention site, implementation process or participant. However, a comparative case study covers multiple cases in a way that produces more generalizable knowledge about causal questions such as "how" and "why" particular programmes or policies succeed or fail. A comparative case study approach may be adopted when it is not feasible to carry out an experimental design and/or when there is a need to understand and explain how features within the context influence the success of programme or policy initiatives, and they involve the analysis and synthesis of the similarities, differences and patterns across two or more cases that share a common focus or goal [36-40]. Within the context of sustainable energy transitions, a comparative multiple case study was adopted because it enables a comparison of various use cases of digitalisation within the energy sector by various actors who see business and socioeconomic value in applying digital technologies such as blockchain and smart grids within the energy sector.

The criteria used in selecting companies covered by the case studies were as follows: application of digital technologies as part of their business models or value chain; the offering of alternative models of production, consumption, or access to energy; and their operations domiciled in a country located in subSaharan Africa. The companies were assessed on the following criteria: innovativeness - use case built around adopting and implementation of digital technologies within the energy sector; business model plan for the successful operation of a business that identifies sources of revenue, the targeted customer base, products, and details of financing; SET compliance - source of electricity generated and consumed must be from renewable energy sources; and socioeconomic inclusiveness - ensure that cost is not a barrier to access for the targeted user base. From the list of companies and projects summarised in Table 2, a detailed assessment of the companies and projects led to the identification of Alliander, Bankymoon and Electron as three companies currently implementing use cases that involves both technologies in a way that closely fits the stated objectives of this study.

\section{Renewable Energy Policy Landscape: Nigeria And South Africa}

Based on evidence obtained from reviewed literature, the renewable energy policy landscape in Nigeria and South Africa differ in terms of maturity and scope. Nigeria has several policies focused on the energy sector, such as the National Energy Policy of 2003 which articulates the government's position on development and exploitation of all Nigeria's energy resources, addressing environmental concerns, energy utilization/efficiency, financing and policy implementation; Electric Power Sector Reform Act (EPSRA) of 2005 which seeks to transform the Nigerian electricity market from a government-owned and monopolistic market to a privatised entity that enables private investors to enter invest in the market and make returns on their investments while supplying electricity to end users; the Energy Commission of Nigeria Act of 1979; Nigeria Renewable Energy Master Plan developed in 2006, which articulates a vision of Nigeria achieving sustainable development through the use of renewable energies; Renewable 
Electricity Policy Guidelines of 2006, aimed at promoting renewable energy in the power sector; and the National Renewable Energy and Energy Efficiency Policy of 2015 [41-44].

In spite of all of these policies and plans, the Nigerian Electricity Regulatory Commission (NERC) expressed its dissatisfaction with the absence of a policy on renewable energy in the country, the government agency complained that the situation is retarding solar energy's contribution to the power supply in Nigeria [44-46]. However, in relations to Nigeria's renewable energy policy landscape, Edomah [20] makes an interesting observation, he argues that there exists a complex relationship between resources, institutions, and political structures in the governance of energy infrastructure; therefore subjecting energy transitions to the influence of government policies implemented within and through institutions; also, there is an increased need for partnership and interaction between public and private institutions in the governance and provision of energy infrastructure. He then concludes that energy infrastructure provision is primarily a political choice; hence, and that technological changes in electricity supply systems are a major catalyst in shaping the kind of energy infrastructure a society ends up with.

In 2011 South Africa initiated policy aimed at supporting renewable energy when the government hosted the 17th Conference of the Parties in Durban (COP17). Its previous efforts to generate electricity from renewable energy sources was done under the instrumentality of the Renewable Energy White Paper and the Renewable Energy Feed-In Tariff (REFIT), this unfortunately suffered setbacks as a result of the lack of political support for their implementation. Subsequently, the South African Government's National Treasury and its Department of Energy launched the renewable energy independent power producer procurement program (REIPPPP) considering the climate change negotiations at the COP 17 in Durban that year. The REIPPPP currently counts as the most successful energy program nationally [47-49]. However, in spite of the well documented benefits of South Africa's energy policies, particularly its renewable energy policies, Sebitosi and Pillay [50] argue that South Africa appears to be caught in a time warp with a weak policy environment, and a power sector that continues to plan its future in the traditional way.

\section{Digitalisation And Sustainable Energy Transitions}

According to Gartner, "Digitalisation is the use of digital technologies to change a business model and provide new revenue and value-producing opportunities; it is the process of moving to a digital business" [14]. Digitalisation should not be confused with mere digitisation. This is because digitisation involves the replacement of a physical thing with a digital version, while digitalisation represents a much more fundamental, and pervasive, transformation, one that seeks to create new sources of value by placing digital information at the core of the business; digitalisation moves beyond simply recording data or using digital tools to support existing business; it requires reshaping the business to harvest value from digital technology use [51]. Digital technologies mediation of sustainable energy transitions involves the adoption and implementation of these class of technologies in ways that leverage their unique characteristics to offer new models of production, distribution and consumption of energy. Particularly, 
digital technologies such as blockchain, smart grids and digital platforms (platformisation) have demonstrated practical capacity for deployment within the energy sector.

\subsection{Smart Grid Solutions}

The Smart Grid is a concept that has been around for many years. Over time, it has evolved significantly to cover a wide range of technological solution with a broad set of functionalities. As a result of the challenges of electricity grids experienced in countries such as the USA, UK, and across Europe over the last decade, there has been an acceleration of deployment of Smart Grid solutions, which has resulted in increasingly decentralised electricity production systems based on renewable energy sources, more energy-efficient behaviour by consumers, and the recent trend of connecting electric vehicles to the energy grid thereby resulting in significant impact on the energy industry in the coming decades [52-55].

Smart Grids are a direct outcome of the digitalisation of energy systems through the adoption and implementation of digital and other advanced technologies for the monitoring and management of electricity transmission from all generation sources, to meet the varying electricity demands of end users [IEA 2001 as cited in 56]. The Department of Energy and the South African National Energy Development Institute (SANEDI), view a Smart Grid as "an electricity network that can intelligently integrate the actions of all users connected to it - generators, consumers and those that do both - in order to efficiently deliver sustainable, economic and secure electricity supplies". While Sustainable Energy Africa [57] defines it as "an electricity network that uses digital and other advanced technologies to monitor and manage the transport of electricity from all generation sources to meet the varying electricity demands of end-users." Also, Niesten and Alkemade [52] view a Smart Grid as an electricity grid that integrates information and communication technologies into the existing electricity network to allow for a two-way flow of information and electricity between generators and consumers. In all of the definitions stated, a common feature of Smart Grids shared by all the definitions is the centrality of digital/ICTs in distinguishing the Smart Grids from the conventional grids; hence, the presence of these advanced technologies in the grid is what makes it 'smart'.

How does a Smart Grid work? It employs innovative products and services that are combined with intelligent monitoring, control, communication, and self-healing technologies to: achieve better facilitation and management of the connections and operations of all sources of energy; provide consumers with more choices that enable them optimise their energy usage and consumption; enable consumers to have access to more information and choice of supply; significantly reduce or eliminate the negative environmental impact of the whole electricity supply system; and deliver improved levels of reliability and security of supply $[52,58-60]$. Sebitosi and Okou [60] lists some of the benefits of smart grids to include the exploitation of dispersed resources (human and natural) through local exchange and storage of surplus electric energy, thereby leading to minimised transmission and distribution costs and losses as well as improved resilience to disruptions through self-sufficiency; they argue that there would also be greater end user engagement in energy investment and management as well as increased potential for more energy efficient social practices. There are several initiatives across Africa that aims to leverage the 
benefits and advantages of Smart Grids in improving access to electricity and overall efficiency of the supply system, prominent examples exist in South Africa spearheaded by agencies such as the Department of Energy and SANEDI.

Smart grids are widely recognised as an enabling technological component required for achieving sustainable energy transitions. However, such transitions have given rise to more complex governmentutility-consumer relationships as evidence from field deployments in various jurisdictions have shown [53-55]. Milchram et al. [53] found that investigated the proposition for smart grid systems in the United Kingdom and the Netherlands in relations to concerns that affect social and moral values such as privacy and justice, they found that smart grids have the potential to effectively address justice issues, for example through the facilitation of small-scale electricity generation and transparent and reliable billing. However, they also found that while the current smart grid designs contribute to cost and energy savings, advance a more equitable and democratic energy system, they may also reinforce distributive and procedural injustices. While investigating stakeholder relationships by examining the role of incumbent utilities for sustainable energy transitions through the use of smart grid in China, Ngar-yin Mah et al. [54] found that China has developed an incumbent-led model for deploying smart grids; also, the major-stateowned grid companies, act as enablers of smart grid deployments; and finally, the two main grid companies also act as a fundamental block to structural changes in socio-technical regimes. Hence, issues identified from previous research efforts into the deployment of smart grids, it is imperative that conscious efforts be made by relevant stakeholders in ensuring that deployment pitfalls are avoided if the full benefits of smart grids would be harnessed for successful sustainable energy transitions particularly across sub-Saharan Africa.

\subsection{Blockchain Technology in the Energy Sector}

Blockchain technology occupies a prime position among digital technologies, it is used to power decentralised storage and sharing of transactional data across a large peer to peer network, where nontrusting members are able to interact with each other without an intermediary, in a verifiable manner [61]. Blockchain technology is presently broadening borders and expectations due to its characteristics of immutability, decentralization, and time-stamped record keeping. Blockchain also has potential for adoption within many areas across several industry segments. The technology is a distributed ledger that may be anonymous and permission-less. It is a time-stamped tamper-proof ledger that has the benefit of being able to remove the need for middlemen thereby eliminating friction and trust related issues among parties involved in transactions executed through a Blockchain ledger [62]. Disintermediation associated with Blockchain technology leads to cost reduction associated with certain business processes since they now become automated and independent self-executing processes as encoded in the smart contracts stored in the ledger.

There are basically three types of Blockchains - public, permissioned, and private [63-65]. The blockchain ledger is not stored in a centralised server, but copied and synchronised among parties of the network in a disintermediated fashion which eliminates the need of a middleman, thereby protecting the ledger from being a single point of failure, which deters any illegitimate tampering, the records stored in the 
blockchain database is protected by cryptography $[62,63,66]$. Blockchain technology is of particular interest because of its unique features some of which includes immutability of data recorded on it, and its ability to remove the need for a middleman from transactions involving two or more parties $[64,65]$. There are three types of Blockchains: Public Blockchain, Private Blockchain, and Consortium or Federated Blockchain.

Table 1

Types of Blockchain networks.

(Source: Author)

\begin{tabular}{|lll|}
\hline Public Blockchain & Private Blockchain & Consortium or Federated Blockchain \\
\hline $\begin{array}{l}\text { Permission open to } \\
\text { anyone to run } \\
\text { Bitcoin/Litecoin full node }\end{array}$ & $\begin{array}{l}\text { Permission not open to } \\
\text { anyone to run full node }\end{array}$ & $\begin{array}{l}\text { Permission only opened to selected } \\
\text { members of the consortium to run full } \\
\text { node }\end{array}$ \\
\hline $\begin{array}{l}\text { Rights to conduct } \\
\text { transactions is granted to } \\
\text { anyone }\end{array}$ & $\begin{array}{l}\text { Rights to conduct } \\
\text { transaction is not granted } \\
\text { to anyone }\end{array}$ & $\begin{array}{l}\text { Rights to conducted transactions is only } \\
\text { granted to selected members of the } \\
\text { consortium }\end{array}$ \\
\hline $\begin{array}{l}\text { Permission to } \\
\text { review/audit the } \\
\text { blockchain is granted to } \\
\text { anyone }\end{array}$ & $\begin{array}{l}\text { Permission to review/audit } \\
\text { the blockchain is not } \\
\text { granted to anyone }\end{array}$ & $\begin{array}{l}\text { Permission to review/audit the } \\
\text { blockchain is granted to only selected } \\
\text { members of the consortium }\end{array}$ \\
\hline
\end{tabular}

Public Blockchain allows everyone to participate with no need for trust relationships among the nodes. Transactions recorded on a public blockchain cannot be altered or cancelled, and the following types of Consensus algorithms are used in the public Blockchain: Proof-of-Work (PoW), Proof-of-Stake (PoS), and Delegated Proof-of-Stake (DPoS). Participation in a public Blockchain is open to anyone without permission. The codes are open to be downloaded by anyone and they can start running a public node on their local device, participate in the consensus process by validating transactions in the network.

Anyone can also read and send transactions on the public Blockchain. Notable examples of public Blockchains include: Bitcoin, Ethereum, Dash, Dodgecoin, and Monero. Public Blockchains have the potential to disrupt current business models through disintermediation, and removal of infrastructure costs which radically reduces the cost of developing and operating decentralised applications (dApps). For Private Blockchain networks, write permissions are centralised to one organisation. Only the owner of the Blockchain reserves the rights and authority to modify the information, with the rest of nodes having only limited access. Practical Byzantine fault tolerance (PBFT) consensus algorithm is used in the Private Blockchain. Examples include database management and auditing applications that are meant for internal use of a single business entity. The Federated Blockchain is set up to be operated under the leadership of a group. Unlike the public Blockchain networks, the process of verifying transactions is not opened to any person with access to the internet. This type of Blockchain network has a higher scalability (faster) and provides more privacy for transactions. Federated Blockchains are mainly used by companies within the financial services industry $[61,66,67]$. 
In relations to sustainable energy transitions and digitalisation of energy systems, blockchain technology is currently being applied in several business use cases that facilitates exchange of assets, resources and value. The most common use case applications of blockchain technology includes tokenisation of energy; disintermediation through peer to peer (P2P) energy trading; rewarding renewable energy adoption; accelerating adoption of electric cars; and reduction and tracking carbon emission. The table below gives a summary of these use cases and companies trying to solve the corresponding problems.

Conjoule is a platform that offers $\mathrm{P} 2 \mathrm{P}$ trading among rooftop photovoltaic cell owners and interested public-sector or corporate buyers; Greeneum is a decentralised and blockchain-based P2P platform for renewable energy, it's GREEN token is a utility asset that incentivizes users to reduce carbon emissions; Grid + facilitates energy asset tokenization, it is a retail provider (i.e., buys on behalf of its customers at wholesale prices from outside) and also offers a P2P trading platform among its customers; LO3 combines smart meters with blockchain at micro-grid levels that aims to revolutionize how energy can be generated, stored, bought, sold and used, all at the local level; Drift is a start-up working to digitize, decentralize, and decarbonize energy systems; Veridium Labs aims to create a new asset class that tokenizes natural capital, each token represents the removal of 1 ton of greenhouse gases from the atmosphere, or equivalent natural capital preservation activities (e.g., conserve 1 sq. meter of biodiverse tropical forest), tokens will be issues for validated projects to be used by firms to conform with environmental impact mitigation regulations, and more generally embed environmental replacements into the cost of their products; WePower is a platform for P2P trading of renewable energy, as well as fund raising for renewable projects by pre-sale of energy to be generated in the future; SolarCoin Foundation aims to foster solar energy generation installations; it awards crypto-coins (for free, similar to air miles) to registered and verified solar energy producers. Each coin represents $1 \mathrm{MWh}$ of produced solar energy [68]; OneWattSolar pays for, installs, owns and operates solar residential energy unit at zero up-front investment by home owners [69]; and Sun Exchange operates a peer-to-peer solar leasing platform through which anyone, anywhere in the world, can own solar energy-producing cells and earn returns by leasing those cells to power businesses and organisations in emerging markets, with installations and maintenance taken care of by Sun Exchange's selected installation partners [70, 71].

In bringing Blockchain technology and Smart Grids together, Alessandra et al. [72] proposes an innovative application of the Blockchain technology in operating a Smart Grid. They demonstrate how the Blockchain may play an important role in facilitating communications, transactions and security among the stakeholders involved in a Smart Grid, thereby providing an enhanced system. Their proposed solution permits for the creation of a decentralised energy market that can lead to significant displacement of the balance of expenditure towards energy investments of distributed resources, while creating a potential redistribution of electricity to new energy market stakeholders, differently from the way the electricity is currently distributed and regulated. They cite the example of TransActive Grid, a New York based energy start-up that created and currently operates a similar peer-to-peer energy sales network based on Blockchain technology in which homes with solar panels on their roof are able to sell energy to neighbours on the same road not having their own solar systems. This is a classic example of the social and solidarity economy model powered by Blockchain technology [72]. 
Wu et al. [73] adopts a different approach in exploring the role of Blockchain technology in operationalising Smart Grids by proposing a method to use Blockchain technology in managing the demand and transaction of electricity supply and consumption within a decentralized power market framework in what they referred to as a "machine-to-machine" power demand response management powered by Blockchain technology. Their proposal explores Blockchain technology in relation to demand side management of a Smart Grid and it presents an example of how blockchain can be used to facilitate machine-to-machine (M2M) interaction by framing an electricity market in the context of demand request. They used Blockchain technology to record data derived from power flow calculation model and electricity price customization and applied smart contract to store transaction data and transfer assets automatically. There is no evidence of a commercially available implementation of their proposed solution which would provide an opportunity for comparison with the approach proposed by Alessandra et al. [72].

In another test implementation of Blockchain Technology on Smart Grids documented by Pop et al. [74], they investigated the feasibility of using decentralised blockchain mechanisms to deliver transparent, secure, reliable, and on-demand energy in producer-consumer setting within a Smart Grids distributed energy network. Their approach employed a blockchain based distributed ledger which stores the energy production-consumption information collected from Internet of Things (IOT) smart metering devices in a tamper proof manner, while the smart contracts defines the expected energy flexibility at the level of each producer or consumer, the corresponding benefits or penalties, and the rules for balancing the energy demand with the energy production at grid level. Their system used consensus-based validation for demand response programs validation and to activate the appropriate financial settlement for the flexibility providers. The prototype was implemented on an Ethereum platform using energy consumption and production traces of several buildings from literature data sets. The prototype results show that a blockchain based distributed demand side management was a feasible option for matching energy demand and production in a Smart Grid.

\section{Sustainable Energy Transitions In Sub-saharan Africa: The Case Of The Sun Exchange, Bankymoon And Onewattsolar}

Two companies leading the way in facilitating access to clean energy through digitalisation of sustainable energy transitions are Sun Exchange (South Africa based start-up) and Onewattsolar (a Nigeria based start-up). The Sun Exchange operates a peer-to-peer platform for financing solar energy system installation and leasing platform. Through their platform, anyone, anywhere in the world, can purchase solar energy-producing cells and earn returns on their investments by leasing those cells to power businesses and organisations in emerging markets, this creates a win-win situation whereby the local communities get reliable, cheap power, and the investors get a steady source of income through the usage fees paid by the consumers in the local communities. The model goes through the following process: Firstly, the Sun Exchange works with a group of solar energy companies as its partners (they may be based in any location around the world), identify projects where a small installation - a micro- 
grid of less than a megawatt - could make a significant impact, for example clinics in rural areas or villages with unstable electricity supply. The next step is the planning and pricing of the installation, the planning and pricing info is made available online for prospective investors to purchase a number of the solar cells in the facility, the investors are allowed to purchase based on their risk appetite. Once the cost for the installation is covered through purchase of solar cells by the investors, the array is constructed and put online within 60 days, the community is given access to the electricity generated by the solar cells for a usage fee in an arrangement that is similar to payment for utilities, and the investors (and the Sun Exchange) get a part of that fee proportionate to their ownership of the array based on agreed revenue sharing arrangements [70].

The Sun Exchange is also responsible for handling the leasing and fee collection alongside insurance and other related paperwork. Onewattsolar provides a solution that essentially mirrors the business model of The Sun Exchange in terms of how the solar installation is funded and returns on investments paid to the investors who finance the installations. Also, Onewattsolar uses blockchain technology through the implementation of a "smart contract" that ensures accurate records of consumption of electricity and billing of consumers for precisely what the consumed. Essentially, a smart contract is a protocol written into the blocks of the blockchain that is intended to digitally facilitate, verify, or enforce the negotiation or performance of a contract; they allow the performance of credible transactions that are trackable and irreversible without the interference or mediation of a third parties $[66,75,76]$.

Bankymoon is a South Africa based software and consulting start-up with expertise in Blockchain technologies. Bankymoon offers consultation services to their clients by analysing existing systems and making recommendations based on the applicable use-cases, they also provide system integration services offering their extensive experience on integrating blockchain technologies through the identification of relevant touch-points within systems, and development of robust adapters using standards-based technologies; and finally, they offer bespoke custom software development for financial services with a blockchain-centric approach $[75,77,78]$. In 2015, Bankymoon made headlines when it announced Bitcoin's first innovative app, the 'Smart Grids and the Blockchain'. Through this app, Bankymoon provides Bitcoin payment gateways to smart metering vendors, allowing utility vendors to accept Bitcoin payments. It also recently launched a crowd-funding platform for public schools, allowing them to gain electricity credits $[79,80]$.

Users of the app provided by Bankymoon are able to top up their smart meters by using the Bitcoin cryptocurrency in real-time. Therefore, this makes it possibility for customers outside the coverage of the traditional banking system to pay for electricity. It also comes with the added benefit of avoiding high transaction fees associated with the traditional banking systems. The challenges faced by suppliers and municipalities within the energy sector in South Africa often leads to conflicts between suppliers and municipalities. This is partly as a result of the conflict prone architecture of the billing systems currently operated. One of the main consequences of this conflict prone billing system architecture is the problem of cost recovery with the attendant consequence of electricity price inflation. Hence, Bankymoon's Blockchain based and Bitcoin powered 'smart meter' solution was developed with the objective of solving 
this problem. Every smart-meter provided by Bankymoon has a unique Bitcoin address. When payment is sent to the smart meter in the form of Bitcoin cryptocurrency, the system automatically computes the tariff and then tops up the smart-meter for the customer. This makes it possible for individuals to literally send utilities such as electricity to anyone using the Bankymoon smart-meter from anywhere in the world by using Bitcoin cryptocurrency. Bankymoon's solution is an innovative approach that liberalises crossborder transactions in a uniquely different way. There is also the possibility for donors to send money directly to the smart-meters supplied by Bankymoon through a crowd-funding platform (Usizo platform) created by the same company for schools in Africa [79]. 
Table 3

Case study assessment matrix

(Source: author)

\section{The Sun Exchange \\ Bankymoon \\ Onewattsolar}

South Africa

Blockchain enabled smart

meters that facilitates

payments for utilities

through the use of

cryptocurrencies

Business
model

Sustainable

Energy

Transition compliance peer-to-peer platform

for financing solar

energy system

installation and

leasing platform.

Two-sided

marketplace that

brings together

financiers and

consumers of

renewable energy.

Crowd fund

installation of solar

energy and lease

generated energy to

consumers, investors

earn returns on

investments through

income generated

from usage fee paid

by consumers.
Payment facilitation

Yes - the solutions

provided by The Sun

Exchange offers

access to electricity to

underserved

communities in South

Africa through the use

of renewable energy. It

also leverages a

flexible and convenient

payment model that

ensures that cost is

not a barrier to access

for users at the bottom

of the society's

socioeconomic

pyramid
Nigeria

peer-to-peer platform for financing solar energy system installation and leasing platform.

Two-sided marketplace that brings together financiers and consumers of renewable energy. Crowd fund installation of solar energy and lease generated energy to consumers, investors earn returns on investments through income generated from usage fee paid by consumers
No - Bankymoon's solution is primarily focused on providing access to energy traditional sources, their solution is more focused on providing access to energy through additional payment source which in this case is made possible by enabling the use of cryptocurrencies. In comparison with Alliander and Electron, the energy consumed by the end-users is not sourced from sustainable sources.
Yes - similar to what The Sun Exchange offers, Onewattsolar's solution also offers access to electricity to underserved communities in Nigeria through the use of renewable energy. It also leverages a flexible and convenient payment model that ensures that cost is not a barrier to access for users at the bottom of the society's socioeconomic pyramid

Socioeconomic
inclusiveness
(cost of
acquisition and
use as a
barrier)

Yes - cost is not a barrier to access and usage for the targeted user base
Yes - cost is not a barrier to access and usage for the targeted user base
Yes - cost is not a barrier to access and usage for the targeted user base 


\section{Discussion}

The quest to achieve sustainable energy transitions is gathering momentum, particularly as digital technologies are acting as transformational catalysts that are disrupting traditional models and leading to the emergence of new models within the energy sector across the world. Africa with its huge infrastructural deficits that has hampered its socioeconomic development over the decades is not being left behind in the pursuit of sustainable energy transitions. Africa's infrastructural deficits is particularly visible in the energy sector across the continent, this has manifested in significant level of underutilisation of its economic potentials which has ultimately resulted in high levels of poverty and unemployment among its population [2, 3]. In terms of level of progress achieved towards sustainable energy transitions on a country by country level, African countries are laggards according to data compiled by the World Economic Forum in their computations of the Energy Transition Index (ETI) rankings. Most African countries are at the bottom of the ETI rankings, with its two largest economies Nigeria scoring 109 and South Africa scoring 114 on an overall ranking of 115 countries [28].

These poor rankings by African countries implies that there are huge opportunities for leapfrogging Africa's energy deficits through the use of technology in ways that can directly usher the continent into a future of successful sustainable energy transitions that relies solely on renewable sources, socioeconomically inclusive by targeting users at the bottom of Africa's socioeconomic pyramid. The World Economic Forum notes that "accelerating the energy transition will require coordinated action across economic, technological and socio-political systems" [28]. Digitalisation of energy systems in combination with renewable energy sources promises a paradigm shift in the quest to improve the socioeconomic outcomes for marginalised societies all over the world, especially in sub-Saharan Africa. The quest to achieve the objectives of the SDGs may not be attainable if the same approach in governance, business and capitalism that may have contributed to creating these problems in the first place is maintained. Hence, there is an urgent need to explore new approaches to achieving the SDGs.

Evidence obtained from the extensive review of relevant literatures indicates that energy generation and distribution models that rely on Blockchain technology are currently being explored around the world, particularly in the context of marketplace where energy generated in micro-grids is being traded. From the comparative assessments of three companies covered in sub-Saharan Africa. A detailed review of their models from publicly available sources (company websites, news articles and YouTube videos) indicates that only two (The Sun Exchange and Onewattsolar) of them effectively fall into the category of companies that have achieved a considerable level of digitalisation of energy production and consumption models that can be said to be compliant with digitally enabled sustainable energy transitions. Both companies rely on renewable energy source solar (energy) for the generation of electricity energy consumed by their users, they also rely on a digital platform based two-sided market that brings together project financiers and recipients whose regular usage fees serves as source of revenue for the investors. This financing model ensures that the users are not excluded based on the huge initial investment costs required for setting up the system. 
Also, Monyei, Adewunmi and Jenkins [81] in their research on off-grid rural electrification in South Africa through the use of solar home systems (which is what is offered by the Sun Exchange and Onewattsolar) argue that policies targeted at non-grid electrification may be practically and ethically flawed because they do not incorporate values into its delivery, they also do not adequately consider factors such as weather variation across areas in which off-grid solar home systems are deployed. Based on their data analysis, they established that solar irradiance stochasticity impacted significantly on the outputs of ssolar home systems, thereby depriving the users of the intended benefits of such systems, their data analysis showed that the varying figures of $7.5 \mathrm{KWh}$ per month for individual households using the offgrid energy systems was poor when compared to the traditional energy grid based average of $45 \mathrm{KWh}$ per month per household.

Currently, the evidence on ground in relations to the digitalisation of sustainable energy transitions in Africa suggests that Africa is still very much in the early stages of adoption and application of digital technologies such as blockchain and smart grids within the energy sector. The current applications as exemplified in the use cases by the three companies covered in this study indicates that Africa's sustainable energy transitions is in a rudimentary or early adoption stage. While it is noteworthy that two out of the three companies covered in this study adopt platformisation in their business model approach in connecting sustainable energy dependent electrification project financiers to end users, it is also important to acknowledge that platformisation at their stage is not an indication of advancement or sophistication in the stage of sustainable energy transitions. Platformisation is a well-established approach to digitalisation of business models [82-84], it is quite effective and transformational but beyond creating a multi-sided (or two-sided in this case) marketplace, Africa's energy transition is yet to enter into the mass adoption stage.

When compared with what is obtainable in more advanced societies, we see an absence of micro-grids that involves multiple energy producers who are able to trade excess energy produced with other consumers. The current approach by The Sun Exchange and Onewattsolar is basically standalone and subsistent in nature, this leads to inherent inefficiencies because there is an absence of a mechanism that determines if the energy generated for any particular user is more or less than what that user requires. If the energy generated is more than what the user requires, there is no way the user can trade the excess, and if less, there is also no way the user can purchase extra from other producers with excess capacity. Hence, the current model suffers from a level of inefficiency that is yet to be quantified. In regard to long term viability of these models, Africa's infrastructural deficits especially within its energy sector provides a fertile ground for these types of projects to thrive considering the gaps they can potentially fill in bringing electricity to underserved communities.

Situating the case studies of digital technologies mediated sustainable energy transitions covered in this research within the context of the policy and regulatory environments in which they are domiciled, it is observed that there is a disconnect existing between industry efforts and the policy environments governing such energy transitions. This disconnect hampers the ability for meaningful proliferation of such initiatives, particularly in ways that would translate to positive and impactful socioeconomic 
benefits across the society, this observation is also buttressed by Edomah [20] who commented that energy infrastructure choices were subject to the influence of prevalent institutional dynamics and structures. Also, the research by Monyei, Adewunmi and Jenkins [81] sheds light on the technical shortcomings of the solar home systems deployed by the Sun Exchange and Onewattsolar, which makes them practically not viable for addressing the incidence of energy poverty suffered who rely on such deployments.

In relations to the solution provided by Bankymoon in South Africa, it depends on electricity being created through traditional energy production models from major South African utility providers such as Eskom which is largely fossil fuel based, the value which Bankymoon's solution offers is more on the payment side of access to electricity, as the case of their Usizo platform shows, for example, needy schools that have Bankymoon meters installed which are Blockchain-aware, allows anybody from around the world to make payments directly to the meter in the cryptocurrency of their choice and fund the energy or water needs of the school. The process of funding utilities for needy organisations through Bankymoon's Usizo platform is fairly straightforward. Bankymoon advertises the organisation that requires funding for utility. When a school is advertised, the amount of Kilowatt-hour $(\mathrm{kWh})$ of electricity required is stated alongside the cost per kWh. For example, school A requires 2,993 kWh at $\$ 0.23$ per kWh, the cryptocurrency payment address/barcode is displayed as part of the information on the school's advert page of the Usizo portal. Once payment is sent to the cryptocurrency address/barcode, the school is automatically given access to electricity through the smart meter because it now has "credit" on it for the amount sent by the donor. Unfortunately, as at the time of conducting this study, it was not possible to ascertain how many payments for utilities or frequency of such payments have been made by donors to needy organisations in South Africa; hence, the level of external dependency cannot be determined at this point.

\section{Conclusion}

Digitalisation of energy systems in combination with renewable energy sources are potential solutions to infrastructural challenges that involves both volatility of energy supply and available capacity. Generally, digital technologies such as blockchain and smart grids can be effectively leveraged to ensure that new energy production and consumption models are socially inclusive and environmentally sustainable. They can also be leveraged to ensure that existing systems can be more efficiently utilised to reduced wastages within the system and make it more transparent and reliable by taking steps such as making consumption of energy adjustable to the fluctuations associated with production, and by replacing the traditional approach that relies on expensive capital investments in physical equipment such as cables, transformer stations and additional production capacity.

Hence, smart grid advocates argue that they are, in terms of socio-economic considerations, an optimal solution to future challenges and therefore, they are beneficial to all. Hence, from the literatures and case study reviewed, the prospects of combining the potentials of smart energy grids and Blockchain technology presents a potentially viable solution that can be explored on a large scale in the quest to achieve the provision of affordable and clean energy to many marginalised societies across sub-Saharan 
Africa. The energy poverty situation across sub-Saharan Africa has also led to the proliferation of private electricity generation, and what the use cases covered in this study (particularly The Sun Exchange and Onewattsolar) research has shown is that there is a commercially viable possibility to digitalise Africa's sustainable energy transitions through the adoption and utilisation of digital technologies such as Smart Grids and Blockchain technology within its energy sector, for new models of production and consumption of electricity among many producers with the large pool of available consumers. This could help Africa bridge the gap in energy poverty and leapfrog the deficits created by the low level of availability of traditional energy grids across sub-Saharan Africa $[81,85]$.

While Blockchain technology in itself does not determine if the energy is 'clean', its role should be seen from the perspective of an 'enabler' because it enables and encourages a new form of energy marketplace which has the potentials of disrupting the traditional energy market which in itself is not clean because it is not based on renewal energy sources that are environmentally friendly and sustainable $[72,76]$. The Bankymoon project of rolling out Blockchain payments based smart meters hold considerable prospects for commercial viability considering that the Blockchain smart meters are being implemented by Bankymoon throughout South Africa, widespread adoption leads to economies of scale which is vital in ensuring that a solution gains traction in a way that ultimately leads to profitability for producers, while also addressing the pervasive energy poverty plaguing the continent. It is yet to be seen how profitable and sustainable this model is, further research would be required in the future to reevaluate the system and other related issues.

\section{Abbreviations}

SDGs sustainable development goals

SSA sub Saharan Africa

GW Gigawatt

ETI Energy Transition Index

EPSRA Electric Power Sector Reform Act

NERC Nigerian Electricity Regulatory Commission

COP17 17th Conference of the Parties

REFIT Renewable Energy White Paper and the Renewable Energy Feed-In Tariff

REIPPPP renewable energy independent power producer procurement program

SANEDI South African National Energy Development Institute

PoW Proof-of-Work

Page 20/27 
PoS Proof-of-Stake

DPoS Delegated Proof-of-Stake

PBFT Practical Byzantine fault tolerance

dApps decentralised applications

P2P peer to peer

M2M machine to machine

loT internet of things

\section{Declarations}

Funding

The research was supported with funding from the Faculty of Management and Economics Internal Grants Agency IGA/FaMe/2020/002

\section{Availability of data and materials}

The datasets supporting the conclusions of this article are included within the article.

\section{Authors' contributions}

All authors contributed to the development, revision and finalization of the article. All authors read and approved the final manuscript.

\section{Competing interests}

The authors declare that they have no competing interests.

\section{Consent for publication}

Not applicable

\section{Ethics approval and consent to participate}

Not applicable. 


\section{References}

1. Lutz W, K C S (2010) Dimensions of global population projections: what do we know about future population trends and structures? Philos Trans R Soc Lond B Biol Sci 365:2779-2791. https://doi.org/10.1098/rstb.2010.0133

2. Clive C (2019) Africa to propel world's population towards 10 bn by 2050 . Financ. Times

3. Farquharson DT (2019) Sustainable Energy Transitions in Sub-Saharan Africa: Impacts on Air Quality, Economics, and Fuel Consumption. Carnegie Mellon University

4. Batinge B, Musango JK, Brent AC (2017) LEAPFROGGING TO RENEWABLE ENERGY: THE OPPORTUNITY FOR UNMET ELECTRICITY MARKETS. South African J Ind Eng 28:32-49. https://doi.org/http://dx.doi.org/10.7166/28-4-1702

5. Chen B, Xiong R, Li H, et al (2019) Pathways for sustainable energy transition. J Clean Prod 228:1564-1571. https://doi.org/https://doi.org/10.1016/j.jclepro.2019.04.372

6. Bharadwaj A, El Sawy OA, Pavlou PA, Venkatraman N (2013) DIGITAL BUSINESS STRATEGY: TOWARD A NEXT GENERATION OF INSIGHTS. MIS Q 37:471-482

7. Yoo Y, Henfridsson O, Lyytinen K (2010) The New Organizing Logic of Digital Innovation: An Agenda for Information Systems Research

8. Denner M-S, Püschel LC, Röglinger M (2018) How to Exploit the Digitalization Potential of Business Processes. Bus Inf Syst Eng 60:331-349. https://doi.org/10.1007/s12599-017-0509-x

9. Hein A, Schreieck M, Riasanow T, et al (2019) Digital platform ecosystems. Electron Mark. https://doi.org/10.1007/s12525-019-00377-4

10. Evans PC, Gawer A (2016) The Rise of the Platform Enterprise: A Global Survey. NY

11. De Reuver M, Sørensen C, Basole RC (2017) The digital platform: a research agenda. J Inf Technol. https://doi.org/10.1057/s41265-016-0033-3

12. Kane G, Palmer D, Phillips A, Kiron D (2015) Is Your Business Ready for a Digital Future? Is Your Business Ready for a Digital Future? MIT Sloan Manag Rev 56:37-44

13. Martini RG, Martins MR (2016) Digital Technologies. In: Digital Technologies \& Future School: Atas do IV Congresso Internacional TIC e Educação 2016. pp 448-456

14. Gray J, Rumpe B (2015) Models for digitalization. Softw. Syst. Model. 14:1319-1320

15. Lu Y (2017) Industry 4.0: A survey on technologies, applications and open research issues. J Ind Inf Integr 6:1-10. https://doi.org/10.1016/j.jii.2017.04.005

16. Townsend JH, Coroama VC (2018) Digital Acceleration of Sustainability Transition: The Paradox of Push Impacts. Sustainability 10:2816. https://doi.org/http://dx.doi.org/10.3390/su10082816

17. Plooy NT du, Brent AC, Kock IH de (2017) Fostering sustainable energy transitions for South Africa's electricity sector: A set of criteria. In: 2017 IEEE Technology \& Engineering Management Conference (TEMSCON). pp 131-136 
18. Dioha MO, Kumar A (2020) Exploring sustainable energy transitions in sub-Saharan Africa residential sector: The case of Nigeria. Renew Sustain Energy Rev 117:109510.

https://doi.org/https://doi.org/10.1016/j.rser.2019.109510

19. Bellos E (2018) Sustainable energy development: How can the tension between energy security and energy transition be measured and managed in South Africa? J Clean Prod 205:738-753. https://doi.org/https://doi.org/10.1016/j.jclepro.2018.08.196

20. Edomah N (2017) Nigeria's energy transitions: policy decisions, influences, and unintended consequences

21. Yin RK (2013) Case study research: Design and methods. Case Study Res Des Methods. https://doi.org/10.1097/FCH.0b013e31822dda9e

22. Cousin G (2005) Case study research. J Geogr High Educ 29:421-427. https://doi.org/10.1080/03098260500290967

23. Yin RK (2003) Case Study Research . Design and Methods. SAGE Publ. 26:93-96

24. ISPY (2018) An African Energy Industry Report:: 2018. Bolton

25. UN (2018) 2018 Energy Statistics Pocketbook. New York

26. Eberhard A, Foster V, Briceño-Garmendia C, et al (2008) AFRICA INFRASTRUCTURE COUNTRY DIAGNOSTIC Underpowered: The State of the Power Sector in Sub-Saharan Africa

27. Mubera S, Jules N, Uwitonze N (2018) Energy Sector Development in Sub Saharan Africa: Case Study of Rwanda. J Fundam Renew Energy Appl 8:6. https://doi.org/10.4172/20904541.1000250

28. World Economic Forum (2019) Insight Report: Fostering Effective Energy Transition, 2019 edition. Geneva

29. Kaseke N, Hosking SG (2013) Sub-Saharan Africa Electricity Supply Inadequacy: Implications. East Afr Soc Sci Res Rev 29:113-132. https://doi.org/DOI:10.1353/eas.2013.0009

30. Fukushige $M$, Yamawaki $H$ (2015) The relationship between an electricity supply ceiling and economic growth: An application of disequilibrium modeling to Taiwan. J Asian Econ 36:14-23. https://doi.org/https://doi.org/10.1016/j.asieco.2014.11.004

31. Ozturk I (2010) A literature survey on energy-growth nexus. Energy Policy 38:340-349. https://doi.org/https://doi.org/10.1016/j.enpol.2009.09.024

32. Shahbaz M, Lean HH (2012) The dynamics of electricity consumption and economic growth: A revisit study of their causality in Pakistan. Energy 39:146-153.

https://doi.org/https://doi.org/10.1016/j.energy.2012.01.048

33. Bos K, Chaplin D, Mamun A (2018) Benefits and challenges of expanding grid electricity in Africa: A review of rigorous evidence on household impacts in developing countries. Energy Sustain Dev 44:64-77. https://doi.org/10.1016/j.esd.2018.02.007

34. Attia B (2018) Millions of urban Africans still don't have electricity: here's what can be done. In: Conversat. http://theconversation.com/millions-of-urban-africans-still-dont-have-electricity-hereswhat-can-be-done-92211. Accessed 31 Oct 2018 
35. Economist (2016) "Power Hungry; Electricity in Africa." Econ 418:42

36. Woodside AG, Wilson EJ (2003) Case study research methods for theory building. J Bus \&amp; Ind Mark 18:493-508. https://doi.org/10.1108/08858620310492374

37. Sanna $P$ (2016) Exploring added value through the service process: a comparative multiple case study. Benchmarking An Int J 23:1249-1263. https://doi.org/10.1108/BIJ-11-2014-0102

38. Lee AS, Method CS (1989) Case Studies as Natural Experiments. Hum Relations 42:117-137

39. Bartlett L, Vavrus F (2017) Comparative Case Studies: An Innovative Approach. Nord J Comp Int Educ 1:5-17. https://doi.org/10.7577/njcie.1929

40. Mills A, Durepos G, Wiebe E (2010) Encyclopedia of Case Study Research

41. Ogbumgbada CC (2018) Developing an effective legal framework for renewable energy utilization in Nigeria. Renew Energy Law Policy RELP 8:45-52

42. Ozoegwu CG, Mgbemene CA, Ozor PA (2017) The status of solar energy integration and policy in Nigeria. Renew Sustain Energy Rev 70:457-471. https://doi.org/https://doi.org/10.1016/j.rser.2016.11.224

43. Emodi NV, Boo K-J (2015) Sustainable energy development in Nigeria: Current status and policy options. Renew Sustain Energy Rev 51:356-381. https://doi.org/https://doi.org/10.1016/j.rser.2015.06.016

44. Gungah A, Emodi NV, Dioha MO (2019) Improving Nigeria's renewable energy policy design: A case study approach. Energy Policy 130:89-100. https://doi.org/https://doi.org/10.1016/j.enpol.2019.03.059

45. MENA Report (2014) Nigeria: NERC condemns absence of renewable energy policy in NIGERIA. MENA Rep

46. Ajayi 00, Ajayi $O 0$ (2013) Nigeria's energy policy: Inferences, analysis and legal ethics toward RE development. Energy Policy 60:61-67. https://doi.org/https://doi.org/10.1016/j.enpol.2013.05.095

47. Rennkamp B, Haunss S, Wongsa K, et al (2017) Competing coalitions: The politics of renewable energy and fossil fuels in Mexico, South Africa and Thailand. Energy Res Soc Sci 34:214-223. https://doi.org/https://doi.org/10.1016/j.erss.2017.07.012

48. Herbst L, Lalk J (2015) A review of the policy documents behind South Africa's Renewable Energy Independent Power Producer Procurement Programme: How its hits and misses impact society. In: 2015 IEEE International Symposium on Technology and Society (ISTAS). pp 1-6

49. Nhamo G, Ho S-Y (2011) Renewable Energy Policy Landscape In South Africa: Moving Towards A Low Carbon Economy. WIT Trans. Ecol. Environ. 143:265-276

50. Sebitosi AB, Pillay P (2008) Grappling with a half-hearted policy: The case of renewable energy and the environment in South Africa. Energy Policy 36:2513-2516. https://doi.org/https://doi.org/10.1016/j.enpol.2008.03.011

51. Orellana S (2017) Digitalizing Collaboration. Res Technol Manag 60:12-14. https://doi.org/http://dx.doi.org/10.1080/08956308.2017.1348125 
52. Niesten E, Alkemade F (2015) How is value created and captured in smart grids? A review of the literature and an analysis of pilot projects. https://doi.org/10.1016/j.rser.2015.08.069

53. Milchram C, Hillerbrand R, van de Kaa G, et al (2018) Energy Justice and Smart Grid Systems:

Evidence from the Netherlands and the United Kingdom. Appl Energy 229:1244-1259. https://doi.org/https://doi.org/10.1016/j.apenergy.2018.08.053

54. Ngar-yin Mah D, Wu Y-Y, Ronald Hills $P$ (2017) Explaining the role of incumbent utilities in sustainable energy transitions: A case study of the smart grid development in China. Energy Policy 109:794-806. https://doi.org/https://doi.org/10.1016/j.enpol.2017.06.059

55. Mah DN, Wu Y-Y, Ip JC, Hills PR (2013) The role of the state in sustainable energy transitions: A case study of large smart grid demonstration projects in Japan. Energy Policy 63:726-737. https://doi.org/https://doi.org/10.1016/j.enpol.2013.07.106

56. Masembe A (2017) Reliability benefit of smart grid technologies: A case for South Africa. J Energy South Africa 26:. https://doi.org/10.17159/2413-3051/2015/v26i3a2124

57. Sustainable Energy Africa (2014) Smart Grids What are Smart grids?

58. GlobalData (2012) Smart Grid for Africa - A Possible Solution to the Economic Troubles in the Region. Global Data Ltd, London

59. Zikalala DP, Chowdhury SP (2015) Prospects and Challenges of Implementing Smart Grid Technologies in South Africa. In: IET Conference Proceedings. The Institution of Engineering \& Technology, Stevenage

60. Sebitosi AB, Okou R (2009) Re-thinking the power transmission model for sub-Saharan Africa. https://doi.org/10.1016/j.enpol.2009.11.025

61. Aruna Sri PSG, Lalitha Bhaskari D (2018) A study on blockchain technology. Int J Eng Technol 7:418-421. https://doi.org/https://doi.org/10.14419/ijet.v7i2.7.10757

62. Gausdal HA, Czachorowski VK, Solesvik ZM (2018) Applying Blockchain Technology: Evidence from Norwegian Companies. Sustain. 10

63. Chan J, Ott V (2018) Are we blockchain ready: a systematic review. ISPIM Innov. Symp. 1-15

64. Biscontini T (2018) Blockchain ( technology ). Salem Press Encycl Sci

65. Crosby. M, Nachiappan, Pattanayak. P, Verma. S K V (2015) BlockChain Technology. Berkeley Eng 35

66. Yli-Huumo J, Ko D, Choi S, et al (2016) Where Is Current Research on Blockchain Technology?-A Systematic Review. PLoS One 11:e0163477

67. Biktimirov MR, Domashev A V, Cherkashin PA, Yu Shcherbakov A (2017) Blockchain Technology: Universal Structure and Requirements. Tekhnicheskaya Informatsiya, Seriya 51:1-4. https://doi.org/10.3103/S0005105517060036

68. Chitchyan R, Murkin J (2018) Review of Blockchain Technology and its Expectations: Case of the Energy Sector

69. GSMA (2019) GSMA Announces Speakers for Mobile 360 Africa. Contify Telecom News 
70. Coldewey D (2017) The Sun Exchange funds solar installations with micro-investments and bitcoin. TechCrunch

71. Escher A (2017) The Sun Exchange presents at Disrupt Berlin Startup Battlefield. TechCrunch

72. Alessandra P, Scarpato N, Di Nunzio L, et al (2018) Smarter City: Smart Energy Grid based on Blockchain Technology Distributed Simulation of Complex Systems View project Industry 4.0 Revolution View project Smarter City: Smart Energy Grid based on Blockchain Technology. Int J Adv Sci Eng Inf Technol 8:298-306. https://doi.org/10.18517/ijaseit.8.1.4954

73. Wu X, Duan B, Yan Y, Zhong Y (2017) M2M Blockchain: The Case of Demand Side Management of Smart Grid. In: 2017 IEEE 23rd International Conference on Parallel and Distributed Systems (ICPADS). pp 810-813

74. Pop C, Cioara T, Antal M, et al (2018) Blockchain Based Decentralized Management of Demand Response Programs in Smart Energy Grids. Sensors 18

75. Oh S-C, Kim M-S, Park Y, et al (2017) Implementation of blockchain-based energy trading system. Asia Pacific J Innov Entrep 11:322-334. https://doi.org/10.1108/APJIE-12-2017-037

76. Andoni M, Robu V, Flynn D, et al (2019) Blockchain technology in the energy sector: A systematic review of challenges and opportunities. Renew. Sustain. Energy Rev. 143-174

77. Kloppenburg S, Boekelo M (2019) Digital platforms and the future of energy provisioning: Promises and perils for the next phase of the energy transition. Energy Res Soc Sci 49:68-73. https://doi.org/10.1016/j.erss.2018.10.016

78. Ferreira JC, Martins AL (2018) Building a Community of Users for Open Market Energy. Energies 11:2330. https://doi.org/http://dx.doi.org/10.3390/en11092330

79. Jackson T (2015) Bitcoin in Africa: Who is catching on? New Afr 54-55

80. Shah A (2018) Fintech is the New Oil in Frontier Markets Like Africa. Bus World

81. Monyei CG, Adewumi AO, Jenkins KEH (2018) Energy (in)justice in off-grid rural electrification policy: South Africa in focus. Energy Res Soc Sci 44:152-171. https://doi.org/https://doi.org/10.1016/j.erss.2018.05.002

82. Gawer EA, Evans PC (2016) The Rise of the Platform Enterprise: A Global Survey. New York

83. Gawer A (2014) Bridging differing perspectives on technological platforms: Toward an integrative framework. Res Policy 43:1239-1249. https://doi.org/https://doi.org/10.1016/j.respol.2014.03.006

84. Kenney M, Zysman J (2016) The Rise of the Platform Economy. Sci Technol 32:61-69. https://doi.org/10.17226/21913

85. Mukonza C, Nhamo G (2018) Wind energy in South Africa: A review of policies, institutions and programmes. J Energy South Africa 29:. https://doi.org/10.17159/2413-3051/2018/v29i2a1433

\section{Table}

Due to technical limitations, table 2 is only available as a download in the Supplemental Files section. 


\section{Supplementary Files}

This is a list of supplementary files associated with this preprint. Click to download.

- Table2.docx 